\title{
Assessing MODIS Land Surface Temperature (LST) Over Jeddah
}

\author{
Mazen Ebraheem Assiri* \\ Department of Meteorology, Faculty of Meteorology, Environment, \\ and Arid Land Agriculture, King Abdulaziz University, \\ Jeddah, Saudi Arabia
}

Received: 18 October 2016

Accepted: 13 February 2017

\begin{abstract}
Surface temperature is an important parameter for environmental as well as climate studies. Weather stations, however, provide limited information about heterogeneous spatial patterns of temperatures over wide areas, and satellite remote sensing is therefore a viable solution. The current study is designed to assess the land surface temperature (LST) as estimated by a moderate resolution imaging spectroradiometer (MODIS) onboard both the Terra and Aqua satellite systems from 2000 to 2014 over Jeddah. Station data from Jeddah airport was retrieved for the study period and statistical analysis was performed. The results of the study show that the correlation coefficient between MODIS day (night) time LST and stationbased maximum (minimum) temperature is 0.40 (0.93) for Aqua and $0.52(0.85)$ for Terra. Overall, the satellite-based minimum LST estimation is much better than maximum LST estimation. The results are further analyzed with respect to population trends and urban growth development in Jeddah. I concluded that satellite-based LST (MODIS Aqua and Terra) has great potential to represent ground station data over Jeddah, Saudi Arabia.
\end{abstract}

Keywords: MODIS LST, Terra, Aqua, Jeddah, Saudi Arabia

\section{Introduction}

Land surface temperature (LST) is an important indicator of surface energy [1]. Many studies have suggested that LST is mainly affected by industrialization, urban growth, population increase, regional climate, and topography [2-4]. According to the United Nations (2014), 54\% of the world's population is living in urban areas [5]. Whereas in 1950 it was only $30 \%$, and it is

*e-mail: massiri1@kau.edu.sa projected that $66 \%$ of the world's population will be living in urban areas by 2050. Saudi Arabia is the largest country in the Middle East whose urban population is also projected to increase by the year 2050 concurrently with the global increase of urban population [5]. More than $85 \%$ of the total population of Saudi Arabia resides in urban areas as of 2014. In addition, the percentage of urban population of Saudi Arabia was $77 \%$ in 1990 , which has increased to $85 \%$ in 2014 , and it is projected that the urban population of Saudi Arabia will increase up to $89 \%$ of the total population by 2050 [5]. Globally, the trend of urbanization and the growth of urban areas are proceeding rapidly [6-7]. Interestingly, it is revealed 
that the global urban population is increased from the global rural population in 2007, and this increasing trend is found to be continued in the preceding years $[5,8]$. The increasing trend in urban population has an essential impact on LST apart from other important environmental concerns. It is therefore very important to monitor the LST in order to better understand the local as well as regional environmental issues.

Numerous studies have been conducted in the past addressing the impacts of LST and urban growth on the environment and society. For example, Rosenthal et al. [9] observed a positive mortality rate ratio of persons aged 65 and older related to heat in New York City during the period 1997 to 2006. Similarly, Smargiassi et al. [10] concluded that the risk of death is greater in areas of higher LST as compared to areas with lower LST in Montreal, Canada. In a separate study, Ryu et al. [11] examined the urban land impacts on Ozone air quality over Seoul, South Korea, and concluded that the boundary layer characteristics and local circulations under fair weather conditions (whereas fair weather condition represent the moderate weather conditions in which the temperatures was neither low nor high) are modified. They also showed that the $\mathrm{O}_{3}$ concentration in the urban area increases due to the urban land-surface forcing. Chun and Guldmann [12] estimated the land surface temperatures from satellite images and developed a 3-D city model with LiDAR data. Their results show that solar radiation, open spaces, vegetation, building roof-top areas, and water strongly impact surface temperatures. They concluded that LST can cause a rise in temperatures, which in turn leads to the increased demand of electricity for air conditioning and thus can raise pollution from power plants as well as greenhouse gas emissions. It is therefore important to investigate the LST for a country like the Kingdom of Saudi Arabia (KSA), where urban growth has been an increasing trend since 1990. Thus wide spatial coverage of the surface temperature of a particular region in order to understand regional environmental and climatic dynamics is essential.

Typically, temperatures are measured at weather stations (point measurements) with very limited spatial coverage as well as limitations in terms of installation at appropriate aerial and surface remoteness. Thus, a point measurement of surface temperature may not be a good representation of spatial temperature pattern of any particular region. During the last few decades, satellite remote sensing has proven its major role in understanding the atmospheric and surface features due to several advantages over traditional measurements, including extensive global coverage and reasonable spatial and temporal resolutions. Many satellite systems, e.g., the advanced very high resolution radiometer (AVHRR) on the National Oceanic and Atmospheric Administration (NOAA) and moderate resolution imaging spectroradiometer (MODIS) onboard Terra and Aqua have been used to study the land surface temperatures in different parts of the world [13]. Thus the advantage of information at high spatial and temporal resolution and on the global scale has attracted many researchers to use satellite data for the retrieval of land surface temperature.

MODIS onboard Aqua and Terra can provide global daily estimates of $1 \mathrm{~km}$ surface skin temperature, commonly known as land surface temperature (LST) [1417]. MODIS LST is derived from the thermal infrared signal received by the sensor that is a combination of radiant temperature of the land surface and the prevailing atmosphere. It is also important to note that land surface emits radiance differently across the thermal spectrum, which mainly depends on its spectral emissivity [18]. Moreover, intervening atmospheric effects may attenuate the radiant energy signal. The MODIS LST retrieval algorithm uses the split window technique to correct the effects of atmosphere in the LST retrieves. This approach uses two thermal bands to capture the signal in the same area of surface to correct LST measurements [19-21]. Thus, different thermal signals can be captured in the same area that is caused by differential absorption of radiation in the atmosphere [22-23]. It is pertinent to mention here that the split-window algorithm used for MODIS data also corrects for emissivity effects by estimating the emissivities in bands 31 and 32 from land cover types [24].

Many studies have used MODIS day and night LST in different regions across the globe and agreed that nighttime LST can be a good alternate of minimum temperature [25-26]. For example, Vancutsem et al. [14] used MODIS night LST over different ecosystems in Africa to estimate minimum temperature. They estimated minimum temperature with root mean square error (RMSE) ranging from $2.1^{\circ} \mathrm{C}$ to $2.76^{\circ} \mathrm{C}$ for all the stations in the study area. Similarly, Fu et al. [27] showed that a linear relationship exists between MODIS nighttime LST and daily minimum temperature with RMSE ranging from $1.77^{\circ} \mathrm{C}$ to $2.78^{\circ} \mathrm{C}$ for an alpine meadow located on the Tibetan Plateau.

The current study investigates the MODIS LST onboard both Terra and Aqua satellite systems. The main objective of the present work is to explore the effectiveness of satellite-based LST over Jeddah as well as to compare the resultant LST both from Terra and Aqua satellites. For this, the monthly products of day- and nighttime MODIS LST (Aqua and Terra) are used. In addition, surface maximum and minimum temperature of Jeddah is obtained from the General Authority of Meteorology and Environmental Protection (GAMEP), KSA. Finally, the resultant LST trend is analyzed in terms of population growth and urban sprawl in the city. It is envisaged that the outcome of the current study will be very useful for policy makers and decision makers for KSA urban development.

\section{Experimental}

\section{Study Area}

Jeddah city, the area of study in this research, is shown in Fig. 1. Overall the city has an arid climate, which retains its warm temperature in winter, ranging from $15^{\circ} \mathrm{C}\left(59^{\circ} \mathrm{F}\right)$ 


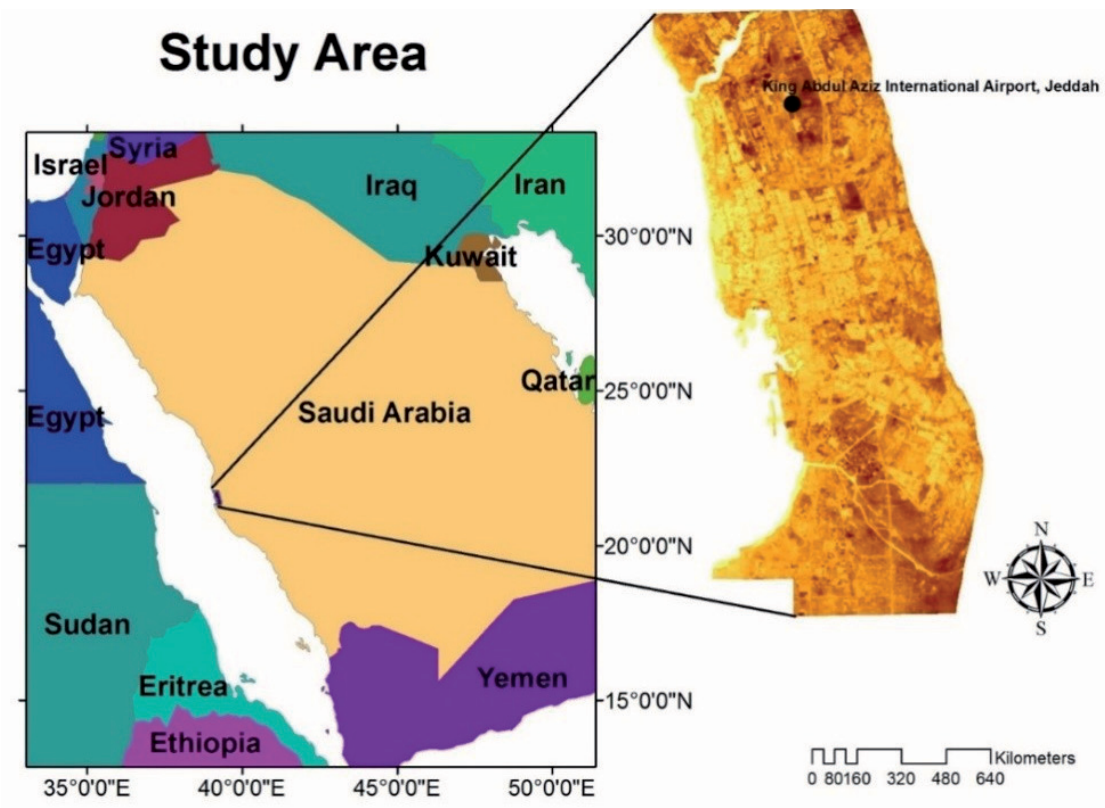

Fig. 1. Location map of King Abdul Aziz International Airport weather station, Jeddah, Saudi Arabia.

at night to $25^{\circ} \mathrm{C}\left(77^{\circ} \mathrm{F}\right)$ in the afternoon, while in summer temperatures range from $43^{\circ} \mathrm{C}\left(109^{\circ} \mathrm{F}\right)$ in the afternoon and dropping to $30^{\circ} \mathrm{C}\left(86^{\circ} \mathrm{F}\right)$ in the evening. In winter heavy thunderstorms are common with several notable incidents of hail. However, rainfall is generally sparse and occurs in small amounts in November and December. The major development of Jeddah started between 1948 to 1956, when it started to serve as KSA`s principal port and current population of the city is approximately 3.58 million [28]. Due to a rapid increase in population, the city has undergone continuous growth of the man-made structures as well as many other population-related features. These planned and unplanned urban developments consequently have an immense impact on LST.

\section{Ground Station Data}

GAMEP is responsible for storing and delivering meteorological data in KSA. GAMEP has a permanent ground station at Jeddah International airport to record and retrieve daily meteorological data. Thus daily maximum and minimum temperature of Jeddah airport station for the study period (2000-14) were obtained from the GAMEP. The station temperature data is recorded as per World Meteorological Organization (WMO) standards, that is at a height of $1.5 \mathrm{~m}$ and at an interval of 10 minutes. As a preliminary quality control, the station temperature data (both daily maximum and minimum) is manually inspected. Outliers and missing values are identified through the Grubbs method [29-30] using statistical Minitab software and are removed from the data series. There were no gaps in the temperature data collected from the GAMEP. Further data homogeneity was checked by using RHtestV3 (climdex.org). In homogeneity there was no daily maximum and minimum temperature data. Then the daily data is averaged on monthly and annual bases for further analysis. Since another objective of the current study is to analyze LST in the scenario of urban development in Jeddah, the population density adjusted with UN 2000 census data was also downloaded from NASA's Socioeconomic Data and Application Centre (SEDAC; sedac.ciesin.columbia.edu/data/set/grump-v1settlement-points/data-download).

\section{MODIS Land Surface Temperature}

For gridded analysis, MODIS data was acquired from the United States Geological Survey (USGS) for the study period (2000-14). The data is freely available from the Land Processes Distributed Active Archive Centre (LPDAAC) [31]. The MODIS sensor is onboard Aqua and Terra spacecraft, ensuring the availability of data day and night. Aqua daytime and nighttime data are available around 13:00 and 03:00 local time, respectively, while Terra daytime and nighttime data are available at around 10:30 and 00:00 local time, respectively. Two MODIS LST products were used in the present work: Aqua MODIS LST (MOD11C3) and Terra MODIS LST (MYD11C3). Both products have spatial resolution of $1 \mathrm{x} 1 \mathrm{~km}$ over the study area. These products have been used in previous studies to estimate air temperature [14, 25-26]. The MODIS LST is derived from two thermal IR bands, 31 (10.78$11.28 \mu \mathrm{m})$ and $32(11.77-12.27 \mu \mathrm{m})$, both of which are used to compensate the effect of atmospheric attenuations in LST. In this study, LST retrieved from daytime passes of the Aqua and Terra satellite systems are considered to be aligned with maximum station temperature records while the minimum station temperature is aligned with the LST retrieved from nighttime passes of Aqua and Terra satellite systems. Correlation coefficient (CC) was employed in order to determine the reliability of satellite data with respect to Jeddah station data. 


\section{Results and Discussion}

Based on 15 years of MODIS Terra and Aqua satellite data, monthly, seasonal, and annual correlations with Jeddah meteorological station are analyzed in this section.

\section{Comparison of the Monthly Temperature}

Fig. 2 highlights the monthly day (night) time LST obtained from MODIS onboard Aqua and Terra satellite systems compared with the monthly averages of maximum

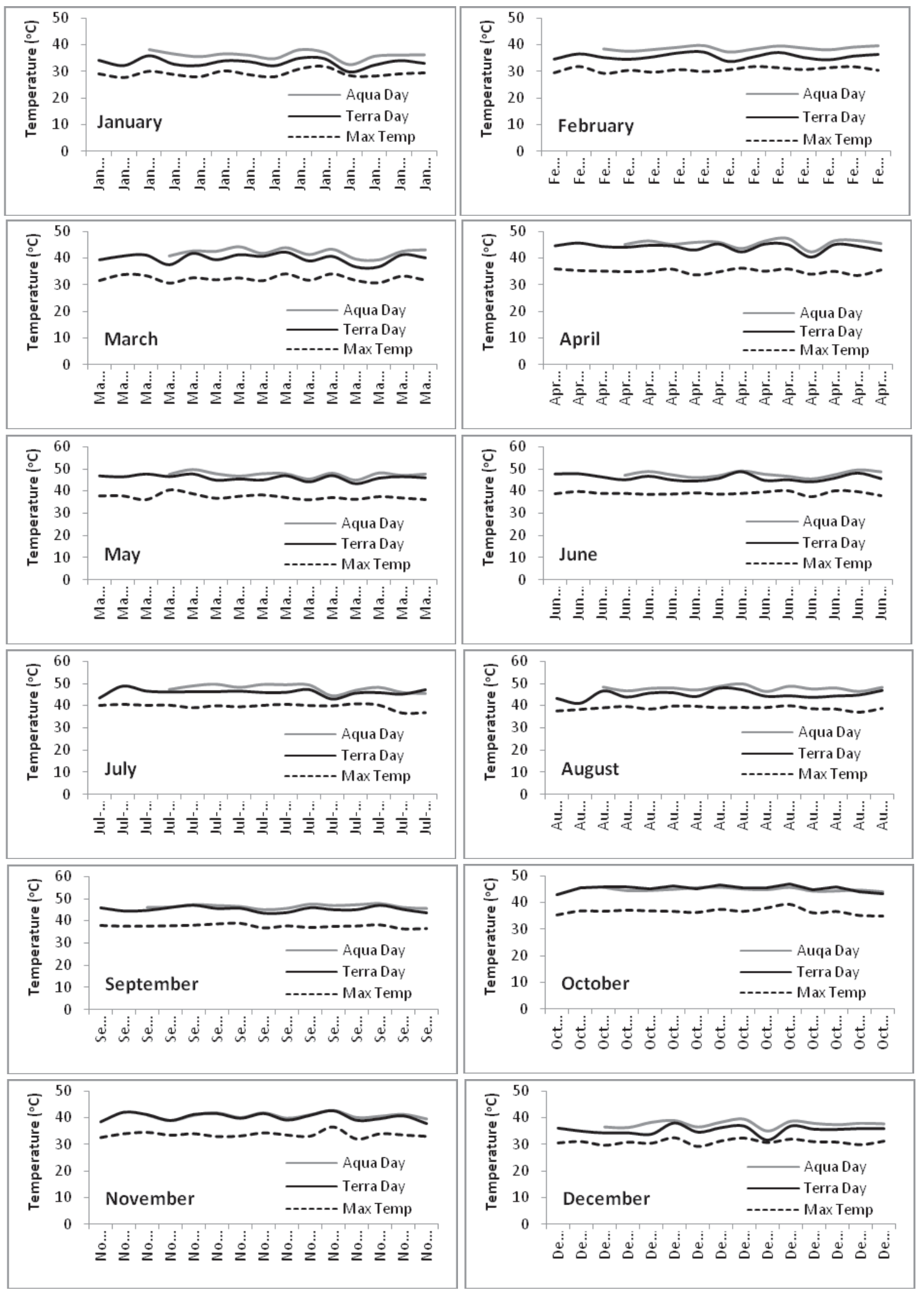

Fig. 2. Monthly plots of Aqua and Terra daytime LST with maximum temperature at Jeddah Station for a period of 15 years (2000-14). 
(minimum) temperature recorded at Jeddah airport weather station. It is clear from Figs 2 and 3 that both Terra and Aqua show strong equivalency with monthly averages of maximum and minimum temperatures. In addition, the MODIS nighttime LST shows a better equivalency with monthly minimum temperature (with the exception of September and October, when it shows a weak relationship) as compared with MODIS daytime LST with maximum temperature. The reason for this is the effect of solar insolation that can change the value
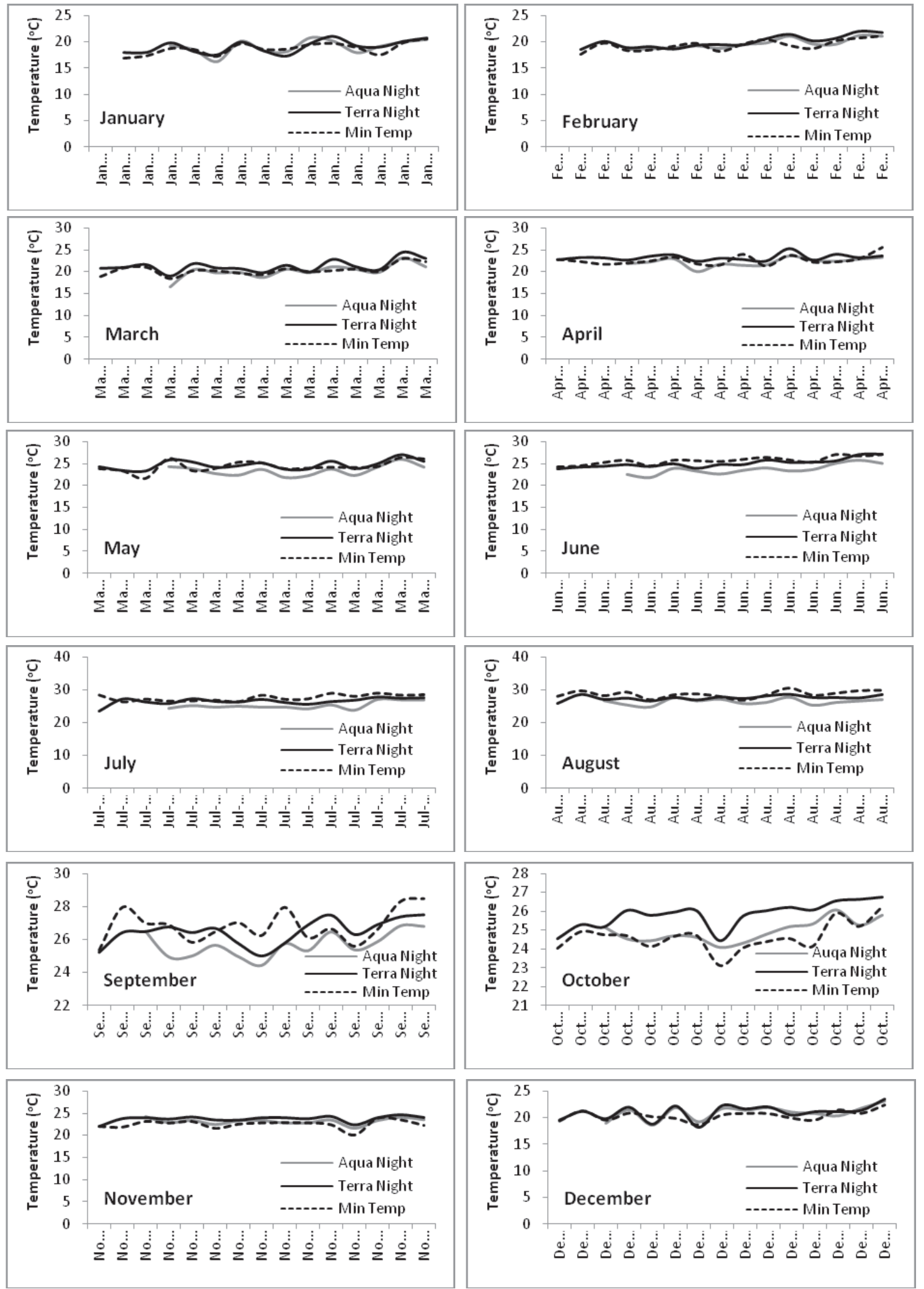

Fig. 3. Monthly plots of Aqua and Terra nighttime LST with minimum temperature at Jeddah Station for a period of 15 years (2000-14). 
of daytime LST due to reemitted long-wave radiation [15]. However, in the absence of solar radiation at night, the relationship between nighttime LST and minimum temperature at Jeddah airport weather station is strong. Thus, the values of daytime LST are normally higher than nighttime LST. Similar results of daytime LST have been reported by other studies conducted in different regions $[14-15,17]$. Nevertheless, there is a strong agreement in the pattern between the satellite-based monthly dayand nighttime estimated LST values with station-based monthly averages of maximum and minimum temperature recorded at Jeddah airport weather station.

Correlation coefficient values between MODIS Terra and Aqua day and nighttime LST and the observed maximum and minimum temperature at Jeddah airport station are given in Table 1. The maximum temperature (daytime pass) values show a correlation coefficient between 0.15 in July to 0.84 in October for the Terra satellite system (Table 1). The correlation between Terra daytime LST and observed maximum temperature averages are strongly significant for most months (with $\mathrm{p}$-values $\leq 0.03$ ), except for the month of May (p-value $=0.07)$ having moderate significance, and the months of January $(p$-value $=0.1)$ and October $(p$-value $=0.98)$ having weak significance. On the other hand, the Terra nighttime LST is significantly correlated with observed minimum temperature averages for April, May, July, August, September, October, and November, whereas the non-significant correlation has been noticed in January, February, March, June, and December (Table 1).

The estimates of the maximum temperature by the Aqua satellite system gives a correlation coefficient between 0.02 (April) to 0.74 (March). Furthermore, only January, March, October, November, and December show

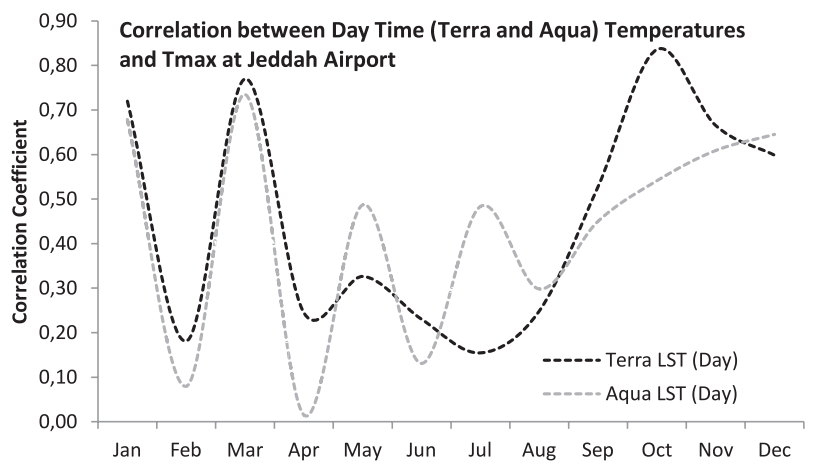

Fig. 4. CC between daytime LST (Aqua and Terra) with maximum temperature for a period of 15 years (2000-14).

a correlation coefficient over 0.5 (Table 1). The strong significant correlations between Aqua daytime LST and maximum observed temperature averages are noticed clearly with p-value less than equal to 0.03 for six months (February, April, May, June, October, and November), while a moderate correlation is observed for the months of August and September $(p$-value $=0.4)$. For the remaining four months ( $p$-value $\geq 0.1$ ) a weak correlation is evident (Table 1). For the minimum temperature (nighttime pass), it is shown in Table 1 that the values of correlation coefficient vary between 0.53 (August) to 0.90 (March) for Aqua. The minimum temperature estimated by Aqua shows only four months (April, August, October, and November) with p-value of less than or equal to 0.05 . However, the significance of the correlations between Aqua nighttime LST and minimum observed temperature averages is not clearly notable as compared to Terra (both day and night).

Table 1. Values of CC and its statistical significance for Terra and Aqua LST and station data for a period of 15 years (2000-14).

\begin{tabular}{|c|c|c|c|c|c|c|c|c|}
\hline \multirow{3}{*}{ Months } & \multicolumn{4}{|c|}{ Terra } & \multicolumn{4}{|c|}{ Aqua } \\
\hline & \multicolumn{2}{|c|}{ Day } & \multicolumn{2}{|c|}{ Night } & \multicolumn{2}{|c|}{ Day } & \multicolumn{2}{|c|}{ Night } \\
\hline & $\mathrm{CC}$ & p-Value & $\mathrm{CC}$ & p-Value & $\mathrm{CC}$ & p-Value & $\mathrm{CC}$ & p-Value \\
\hline Jan & 0.72 & 0.1 & 0.80 & 0.32 & 0.68 & 0.13 & 0.79 & 0.82 \\
\hline Feb & 0.18 & 0.00 & 0.78 & 0.38 & 0.08 & 0.00 & 0.74 & 0.24 \\
\hline Mar & 0.77 & 0.00 & 0.86 & 0.97 & 0.74 & 0.47 & 0.90 & 0.40 \\
\hline Apr & 0.24 & 0.00 & 0.46 & 0.00 & 0.02 & 0.03 & 0.59 & 0.04 \\
\hline May & 0.33 & 0.07 & 0.76 & 0.05 & 0.49 & 0.01 & 0.62 & 0.46 \\
\hline June & 0.23 & 0.00 & 0.81 & 0.87 & 0.13 & 0.03 & 0.88 & 0.07 \\
\hline Jul & 0.15 & 0.00 & 0.12 & 0.02 & 0.48 & 0.10 & 0.57 & 0.37 \\
\hline Aug & 0.25 & 0.00 & 0.64 & 0.01 & 0.30 & 0.04 & 0.53 & 0.05 \\
\hline Sep & 0.53 & 0.00 & 0.43 & 0.01 & 0.45 & 0.04 & 0.65 & 0.08 \\
\hline Oct & 0.84 & 0.98 & 0.73 & 0.04 & 0.54 & 0.00 & 0.83 & 0.01 \\
\hline Nov & 0.67 & 0.03 & 0.69 & 0.01 & 0.61 & 0.03 & 0.78 & 0.00 \\
\hline Dec & 0.60 & 0.00 & 0.74 & 0.74 & 0.65 & 0.23 & 0.65 & 0.65 \\
\hline
\end{tabular}




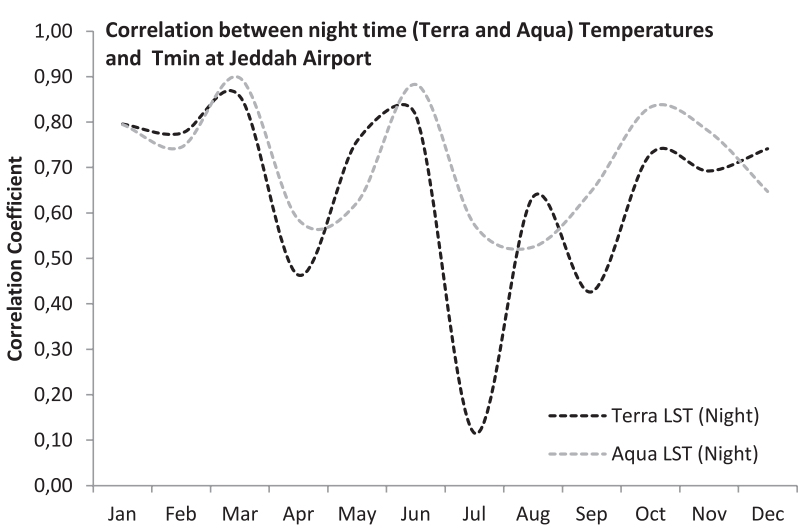

Fig. 5. CC between nighttime LST (Aqua and Terra) with minimum temperature for a period of 15 years (2000-14).

The correlation coefficient between daytime LST (from both Terra and Aqua) and maximum temperature averages recorded at Jeddah airport station is illustrated in Fig. 4. The daytime LST of both Aqua and Terra (Terra being strongly correlated as compared with Aqua) show consistent behavior for the period between September and June. Similarly, the pattern of the correlation coefficient between nighttime LST (from both Terra and Aqua) is shown in Fig. 5, which clearly indicates that of the nighttime LSTs of both Aqua and Terra, Aqua gives better estimates as compared with Terra, and shows a consistent pattern for most months. These results are very encouraging and could drive the use of satellite-based LST for environmental research as well as for climate models.

\section{Comparison of Seasonal Temperatures}

A seasonal comparison between Terra and Aqua LST is also performed in this study. Four seasons have been defined: winter (December-February), spring (MarchMay), summer (June-August), and autumn (SeptemberNovember). Table 2 gives winter, spring, summer, and autumn correlation coefficient values of maximum and minimum of seasonal averages for Jeddah airport station, and day- and nighttime LST retrieved from both Terra and Aqua satellite systems. The correlation coefficient values range between 0.28 and 0.91 . The lowest correlation coefficient values are noticed for daytime LST of summer, both for Aqua (0.36) and Terra (0.28) satellite estimates, which are agreed to the monthly analysis for summer months. The strongest correlation $(0.91)$ is seen in the

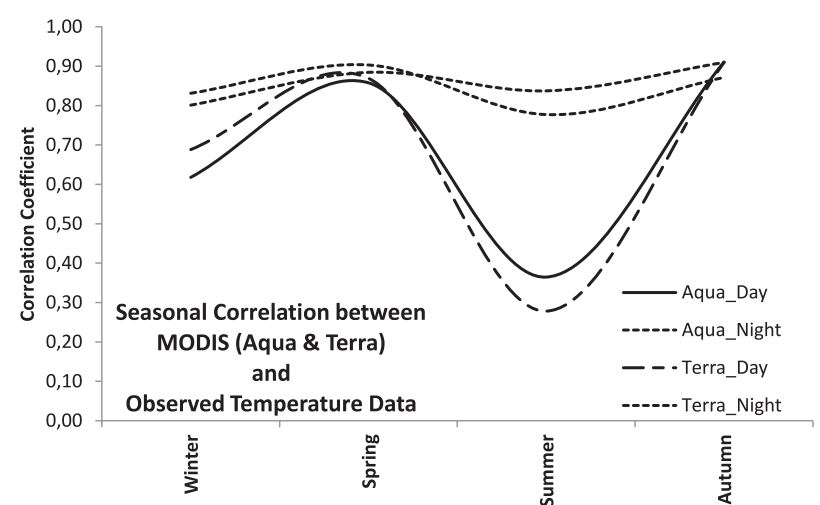

Fig. 6. Seasonal values of CC between day and nighttime LST (Aqua and Terra) with maximum and minimum temperatures for a period of 15 years (2000-14).

autumn result for Aqua day and night LST, while for Terra day and night LST the strongest correlation is seen in autumn (0.91) and spring (0.9) seasons, respectively. Table 2 shows that both systems perform well for all seasons except maximum seasonal summer temperatures.

The overall seasonal trend of correlation values between satellite-based LST and ground-based temperature seasonal averages are depicted in Fig. 6. It is clear that the performance of retrieving minimum seasonal temperature is better than the maximum seasonal temperature using both satellites. In other words, estimating nighttime seasonal averages of LST shows the strongest correlation with their peers observed at Jeddah airport station for all seasons. However, the value of correlation coefficient between maximum seasonal averages and daytime LST values retrieved from both Terra and Aqua systems are significantly low except in the spring season. This clearly indicates the daytime effect of temperature on satellite data retrieval.

\section{Comparing Annual Temperatures}

The annual averages of maximum and minimum temperature have been derived from ground-based data and satellite data for the entire study period (2000-14). The comparison analysis (correlation coefficient) between Terra and Aqua day- and nighttime LST averages and ground-based maximum and minimum temperature averages has been carried out and are shown in Table 3. It can be seen clearly that the correlation coefficient varies between 0.82 (lowest) and 0.99 (highest). Both the lowest

Table 2. Seasonal values of CC for Aqua and Terra LST and maximum and minimum temperatures for a period of 15 years (2000-14).

\begin{tabular}{|c|c|c|c|c|}
\hline & Winter Correlation & Spring Correlation & Summer Correlation & Autumn Correlation \\
\hline Aqua Day LST & 0.62 & 0.86 & 0.36 & 0.91 \\
\hline Aqua Night LST & 0.80 & 0.88 & 0.84 & 0.91 \\
\hline Terra Day LST & 0.69 & 0.87 & 0.28 & 0.91 \\
\hline Terra Night LST & 0.83 & 0.90 & 0.78 & 0.87 \\
\hline
\end{tabular}


Table 3. Annual values of CC for Aqua and Terra LST and maximum and minimum temperatures for a period of 15 years (2000-14).

\begin{tabular}{|c|c|c|c|c|}
\hline Year & $\begin{array}{c}\text { Aqua Day } \\
\text { LST }\end{array}$ & $\begin{array}{c}\text { Aqua Night } \\
\text { LST }\end{array}$ & $\begin{array}{c}\text { Terra Day } \\
\text { LST }\end{array}$ & $\begin{array}{c}\text { Terra Night } \\
\text { LST }\end{array}$ \\
\hline 2000 & & & 0.87 & 0.83 \\
\hline 2001 & & 0.91 & 0.98 \\
\hline 2002 & 0.99 & 0.96 & 0.94 & 0.98 \\
\hline 2003 & 0.93 & 0.93 & 0.93 & 0.98 \\
\hline 2004 & 0.96 & 0.93 & 0.96 & 0.95 \\
\hline 2005 & 0.96 & 0.95 & 0.95 & 0.96 \\
\hline 2006 & 0.89 & 0.94 & 0.91 & 0.95 \\
\hline 2007 & 0.95 & 0.92 & 0.92 & 0.96 \\
\hline 2008 & 0.97 & 0.94 & 0.95 & 0.93 \\
\hline 2009 & 0.91 & 0.92 & 0.88 & 0.96 \\
\hline 2010 & 0.82 & 0.93 & 0.84 & 0.93 \\
\hline 2011 & 0.96 & 0.87 & 0.94 & 0.96 \\
\hline 2012 & 0.95 & 0.96 & 0.93 & 0.97 \\
\hline 2013 & 0.94 & 0.96 & 0.94 & 0.95 \\
\hline 2014 & 0.93 & 0.95 & 0.95 & 0.95 \\
\hline
\end{tabular}

and highest correlation coefficients are found between the maximum annual average and daytime LST estimated from Aqua for the 2010 and 2002, respectively. Terra, however, shows the minimum correlation coefficient (0.83) for the nighttime LST values for 2000 while the maximum value of correlation (0.98) is also noticed for the nighttime LST values, but for multiple years, that is 2001, 2002, and 2003.

The overall seasonal trend of correlation values between satellite-based (Aqua and Terra) LST and ground-based temperature (recorded at Jeddah airport station) values are highlighted in Fig. 7. It is evident that correlation coefficient between ground-based minimum

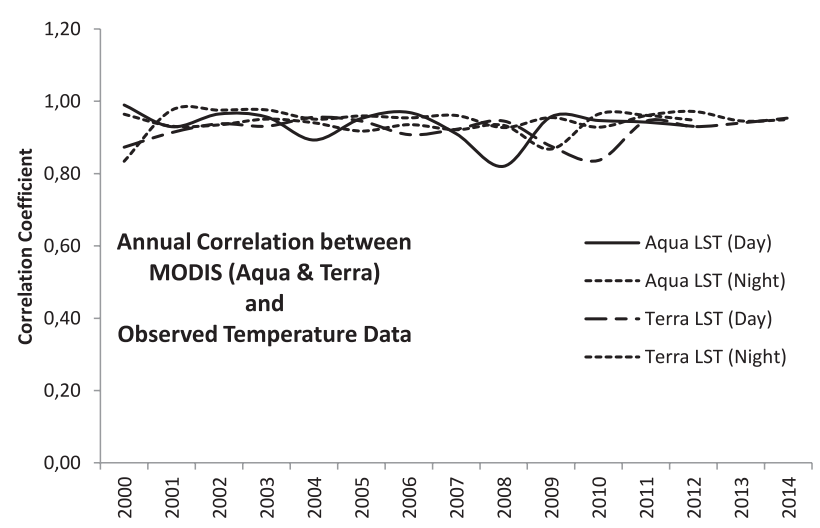

Fig. 7. Annual values of CC between day and nighttime LST (Aqua and Terra) with maximum and minimum temperatures for the study period (2000-14). temperature and nighttime LST from both Terra and Aqua systems is moderately high and consistent for the study period (2000-14). The result of increasing trends of nighttime LST and minimum temperature are reported in previous studies [32]. However, the values of correlation coefficient between maximum temperature recorded at Jeddah airport station and daytime LST values retrieved from both Terra and Aqua are unstable. This clearly indicates the daytime effect of temperature on satellite data retrieval. Furthermore, it is evident from the results that both Terra day- and nighttime LSTs have very strong correlations with maximum and minimum temperatures at an annual scale (Table 3).

\section{Analysis between LST and Urban Development}

Finally, analyses were also performed between LST and urbanization. In the past few years, studies [e.g., 2, 4] have suggested that the LST is mainly affected by urbanization. Saudi Arabia, being the largest country in the Middle East, is no exception since as of 2014 more than $85 \%$ of the total population of the country resides in urban areas. Jeddah, the second largest city of KSA, has been undergoing immense urbanization during the last two decades. This essentially has increased the population of the city from approximately 2 million in 1990 to 3.97 million in 2014 [33]. The urban development of Jeddah has been analyzed using Landsat satellite data. For this, data from the thematic mapper (TM) onboard Landsat 5 for 1984 and 2013 have been downloaded from the USGS. Image processing software ERDAS Imagine version 9.0 is used to apply supervised classification by defining signatures on the basis of the principal component analysis (PCA), normalized difference vegetation index (NDVI), and visual interpretation. PCA and NDVI are used to extract specific training sites for various land use land cover classes (vegetation cover, urban area, bare soil, water body, rock, structure, and sand), while the maximum likelihood supervised classification technique is used to extract land use land cover information. The results of the analysis show that, in Jeddah between 1984 and 2013:

- Vegetation cover has increased from $1.74 \%$ to $2.61 \%$.

- Urban area has increased from $16.05 \%$ to $21.65 \%$.

- Bare soil has increased from $52.81 \%$ to $56.50 \%$.

- Water body has decreased from $1.23 \%$ to $0.75 \%$.

- Rock area has decreased from $14.23 \%$ to $7.63 \%$.

- Concrete structure has decreased from $13.74 \%$ to $10.69 \%$.

- Sand area has decreased from $0.19 \%$ to $0.15 \%$.

These results clearly indicate urban growth in Jeddah during the past three decades. The analysis of the station data from Jeddah airport shows that the average annual temperature of the city has increased from $28.62^{\circ} \mathrm{C}$ in 1980 to $29.86^{\circ} \mathrm{C}$ in 2014 . Similarly, MODIS LST data analysis shows an increasing trend from $32.33^{\circ} \mathrm{C}$ for 2000 to $32.59^{\circ} \mathrm{C}$ for 2014 . Although this is a minor increase in LST, considering the 14 years of MODIS data this change can easily be associated with urbanization in the city. 


\section{Conclusions}

The current study was designed to analyze LST for 2000 to 2014 from MODIS onboard Aqua and Terra satellites, over Jeddah, Saudi Arabia. Statistical methods were employed to obtain the correlation coefficient between MODIS (Aqua and Terra) LST and the maximum and minimum temperatures obtained from Jeddah airport weather station. Overall, results of the current study show that MODIS (Aqua and Terra) nighttime LST has consistent and high correlations with station-based minimum temperature as compared to daytime LST. In addition, the results of the annual study clearly show (Table 3) that MODIS nighttime LST is highly correlated with ground-based minimum temperature $(0.93$ for Aqua and 0.85 for Terra) as compared to daytime LST $(0.40$ for Aqua and 0.52 for Terra). A similar trend can also be seen from the results of monthly analysis (Figs 2 and 3), where MODIS nighttime LST is highly correlated with ground-based minimum temperature as compared to daytime LST.

However, an analysis of seasonal results (Table 2) shows that, apart from expected high correlation between MODIS nighttime LST and minimum ground temperature, the impact of extreme weather is also very important. For example, MODIS (Aqua and Terra) LST (day and night) is highly correlated with ground temperature for autumn and spring as compared to summer and winter. It is therefore concluded that MODIS onboard both Aqua and Terra systems is competent enough to estimate LST over the study area. In addition, the MODIS nighttime LST (Aqua being better than Terra) estimation is better than the daytime LST (Terra being better than Aqua) estimation. Thus, satellite-based LST (MODIS Aqua and Terra) has a great potential to represent ground station data over Jeddah, Saudi Arabia. Furthermore, the increasing trend in urban population has an essential impact on LST apart from other important environmental concerns. It is therefore very important to monitor the LST in order to better understand the local as well as regional environmental issues.

\section{Acknowledgements}

This project was funded by the Deanship of Scientific Research (DSR), King Abdulaziz University, Jeddah, under grant No. G-1437-155-623. The author therefore acknowledges with thanks DSR technical and financial support.

\section{References}

1. LI Z.-L., TANG B.-H., WU H., REN H., YAN G., WAN Z., SOBRINO J.A. Satellite derived land surface temperature: Current status and perspectives. Remote Sensing of Environment, 131, 14, 2013.

2. GILL S.E., HANDLEY J.F., ENNOS A.R., PAULEIT S., THEURAY N., LINDLEY S. Characterising the urban environment of UK cities and towns: A template for landscape planning. Landscape and Urban Planning, 87, $210,2008$.

3. KOLOKOTRONI M., GIRIDHARAN R. Urban heat island intensity in London: An investigation of the impact of physical characteristics on changes in outdoor air temperature during summer. Solar Energy, 82, 986, 2008.

4. ROSENZWEIG C., SOLECKI W. D., PARSHALL L., CHOPPING M., POPE G., GOLDBERG R. Characterizing the urban heat island in current and future climates in New Jersey. Environmental Hazards, 6, 51, 2005.

5. World Urbanization Prospectus The 2014 Revision Highlights. Available online: http://esa.un.org/unpd/wup/ Highlights/WUP2014-Highlights.pdf (Accessed 02 March 2015).

6. GAGO E.J., ROLDAN J., PACHECO-TORRES R., ORDÓÑEZ J. The city and urban heat islands: A review of strategies to mitigate adverse effects. Renewable and Sustainable Energy Reviews, 25, 749, 2013.

7. VARDOULAKIS E., KARAMANIS D., FOTIADI A., MIHALAKAKOU G. The urban heat island effect in a small Mediterranean city of high summer temperatures and cooling energy demands. Solar Energy, 94,128, 2013.

8. MADLENER R., SUNAK Y. Impacts of urbanization on urban structures and energy demand: what can we learn for urban energy planning and urbanization management? Sustainable Cities and Society, 1, 45, 2011.

9. ROSENTHAL J.K., KINNEY P.L., METZGER K.B. Intraurban vulnerability to heat-related mortality in New York City, 1997-2006. Health \& Place, 30, 45, 2014.

10. SMARGIASSI A., GOLDBERG M.S., PLANTE C., FOURNIER M., BAUDOUIN Y., KOSATSKY T. Variation of daily warm season mortality as a function of micro-urban heat islands. J. Epidemiol. Community Health, 63 (8), 659, 2009.

11. RYU Y.H., BAIK J.J., KWAK K.H., KIM S., MOON N. Impacts of urban land-surface forcing on ozone air quality in the Seoul metropolitan area. Atmospheric Chemistry and Physics, 13, 2177, 2013.

12. CHUN B., GULDMANN J.M. Spatial statistical analysis and simulation of the urban heat island in high-density central cities. Landscape and Urban Planning, 125, 76, 2014.

13. WU H., YE L.P., SHI W.Z., CLARKE K.C. Assessing the effects of land use spatial structure on urban heat islands using HJ-1B remote sensing imagery in Wuhan, China. International Journal of Applied Earth Observation and Geoinformation, 32, 67, 2014.

14. VANCUTSEM C., CECCATO P., DINKU T., CONNOR S.J. Evaluation of MODIS land surface temperature data to estimate air temperature in different ecosystems over Africa. Remote Sensing of Environment, 114, 449, 2010.

15. BENALI A., CARVALHO A.C., NUNES J.P., CARVALHAIS N., SANTOS A. Estimating air surface temperature in Portugal using MODIS LST data. Remote Sensing of Environment, 124, 108, 2012.

16. LIN S., MOORE N.J., MESSINA J.P., DEVISSER M.H., WU J. Evaluation of estimating daily maximum and minimum air temperature with MODIS data in east Africa. International Journal of Applied Earth Observation and Geoinformation, 18, 128, 2012.

17. ZHU W., LU A., JIA S. Estimation of daily maximum and minimum air temperature using MODIS land surface temperature products. Remote Sensing of Environment, 130, $62,2013$.

18. OYLER J., DOBROWSKI S., HOLDEN Z., RUNNING S. Remotely Sensed Land Skin Temperature as a Spatial Predictor of Air Temperature across the Conterminous United 
States. Journal of Applied Meteorology and Climatology, 55, 1441, 2016.

19. WAN Z.M., DOZIER J. A generalized split-window algorithm for retrieving land- surface temperature from space. IEEE Transactions on Geoscience and Remote Sensing, 34 (4), 892, 1996.

20. WAN Z.M., ZHANG Y.L., ZHANG Q.C., LI Z.L. Validation of the land-surface temperature products retrieved from Terra Moderate Resolution Imaging Spectroradiometer data. Remote Sensing of Environment, 83 (1-2), 163, 2002.

21. WAN Z. MODIS land surface temperature products users' guide. University of California, Santa Barbara: Santa Barbara, CA, USA, 2007.

22. PINHEIRO A.C.T., MAHONEY R., PRIVETTE J.L., TUCKER C.J. Development of a daily long-term record of NOAA-14 AVHRR land surface temperature over Africa. Remote Sensing of Environment, 103 (2), 153, 2006.

23. ATITAR M., SOBRINO J.A. A split-window algorithm for estimating LST from Meteosat 9 data: Test and comparison with in situ data and MODIS LSTs. IEEE Geoscience and Remote Sensing Letters, 6 (1), 122, 2009.

24. SNYDER W.C., WAN Z., ZHANG Y., FENG Y.Z. Classification-based emissivity for land surface temperature measurement from space. International Journal of Remote Sensing, 19 (14), 2753, 1998.

25. JONES P., JEDLOVEC G., SUGGS R., HAINES S. Using MODIS Ts to estimate minimum air temperatures at night. $13^{\text {th }}$ Conference on Satellite Meteorology and Oceanography, Norfolk, VA: AMS 4.13, 2004.
26. MOSTOVOY G.V., KING R.L., REDDY K.R., KAKANI V.G., FILIPPOVA M.G. Statistical estimation of daily maximum and minimum air temperatures from MODIS Ts data over the state of Mississippi. GIScience and Remote Sensing, 43 (1), 78, 2006.

27. FU G., SHEN Z.X., ZHANG X.Z., SHI P.L., ZHANG Y.J., WU J.S. Estimating air temperature of an alpine meadow on the Northern Tibetan Plateau using MODIS land surface temperature. Acta Ecologica Sinica, 21, 8, 2011.

28. Population Census Organization, Statistics Division 2015. Kingdom of Saudi Arabia.

29. GRUBBS F.E. Sample Criteria for Testing Outlying Observations. The Annals of Mathematical Statistics, 21 (1), 27, 1950.

30. GRUBBS F.E. Procedures for Detecting Outlying Observations in Sample. Technometric, 11 (1), 1, 1969.

31. The Land Processes Distributed Active Archive Center (LP DAAC). Available online: https://lpdaac.usgs.gov/ (accessed on 17 October 2016).

32. ALMAZROUI M., ISLAM M.N., ATHAR H., JONES P.D., RAHMAN M.A. Recent climate change in the Arabian Peninsula: annual rainfall and temperature analysis of Saudi Arabia for 1978-2009. International Journal of Climatology, 32, 953, 2012.

33. http://www.stats.gov.sa/en/sites/default/files/cdsi_data/ yb50/Tabels/Chapter2/Table2-3.htm (accessed on 28 November 2016). 